\title{
The Impacts of Area-Based Policies on Essential Retail in Vulnerable Areas
}

\author{
Cristina Mateos-Mora ${ }^{1,2, *(\mathbb{D})}$, María Rosa Herrera-Gutiérrez ${ }^{1,3}$ ID $_{\text {and Cristina González-Benítez }}{ }^{1}$ \\ 1 Centre for Sociology and Urban Policies, The Urban Governance Lab, Pablo de Olavide University, \\ 41013 Sevilla, Spain; mrherrer@upo.es (M.R.H.-G.); cgonben2@alu.upo.es (C.G.-B.) \\ 2 Department of Sociology, Pablo de Olavide University, 41013 Sevilla, Spain \\ 3 Department of Social Work and Social Services, Pablo de Olavide University, 41013 Sevilla, Spain \\ * Correspondence: cmatmor@upo.es
}

Citation: Mateos-Mora, C.; Herrera-Gutiérrez, M.R.;

González-Benítez, C. The Impacts of Area-Based Policies on Essential Retail in Vulnerable Areas. Sustainability 2021, 13, 8023. https://doi.org/10.3390/su13148023

Academic Editors: Marc A. Rosen and Gideon Baffoe

Received: 31 March 2021

Accepted: 14 July 2021

Published: 19 July 2021

Publisher's Note: MDPI stays neutral with regard to jurisdictional claims in published maps and institutional affiliations.

Copyright: (c) 2021 by the authors. Licensee MDPI, Basel, Switzerland. This article is an open access article distributed under the terms and conditions of the Creative Commons Attribution (CC BY) license (https:/ / creativecommons.org/licenses/by/ $4.0 /)$.

\begin{abstract}
Since the 1990s, urban regeneration has emerged as the main initiative of the European Territorial Development Strategy. A series of integrated urban regeneration policies have subsequently been implemented to redress the socio-territorial imbalance in urban areas by improving the structure of opportunities available to inhabitants. The aim of the current paper is to evaluate the effect of such policies of proximity on the "essential retail trade" in neighborhoods in Andalusia. A quasi-experimental methodology was applied using the Difference in Differences (DiD) technique in order to ascertain the changes attributed to the intervention of the projects. In addition, change trends were analyzed using repeat measurements models for each calculated indicator and in the different considered contexts. The findings show an increase in the density and diversity of essential retail businesses in experimental and control areas. We found that in general, intervention had no significant effect on essential retail trade. However, the results do indicate that the impact of these plans is conditioned by the possible effect of different contexts and their specific dynamics (historical districts of large cities or towns on the one hand or peripheral suburbs on the other). The study may contribute to improving the design of integrated policies by controlling for the specificities of urban areas targeted by intervention.
\end{abstract}

Keywords: essential retail; area-based policies; vulnerable areas; quasi-experimental; difference in differences; impact evaluation

\section{Introduction}

Since the 1990s, urban regeneration has played a key role within the framework of the EU's Territorial Development Strategy. Accordingly, a series of policies have been implemented that are aimed mainly at correcting the processes of socio-territorial imbalance in urban areas. In Spain, the emergence of such policies began decisively in 1994 with the launch and development of the URBAN programs [1,2]. In line with EU guidelines for urban interventions, the different territorial levels (local, regional, national, etc.) have progressively accumulated recommendations and experience regarding the practice of urban regeneration and what the processes of integrated intervention in neighborhoods entail. The purpose of these initiatives is to improve "quality of life in neighbourhoods with high levels of socio-spatial vulnerability, through a comprehensive repertoire of actions aimed at social inclusion, economic development, and physical space, focusing particularly on the recovery of run-down areas, usually due to the cessation of industrial activity" [3] p. 70.

In this vein, various programs have been promoted in recent years that have been aimed at specific territorial areas (such as neighborhoods) in the region of Andalusia. These programs are in contrast to other, more sector-focused public interventions that seek to redress inequalities by providing assistance and services to individuals and households. The theory behind the type of intervention examined here is that it must be enacted in specific territorial areas because their problems stem as much from the circumstances that 
characterize their residents (the concentration of inequalities) as they do from the specific traits that shape them as a structure of opportunities and go beyond the resources and capabilities of the residents when they are considered individually $[4,5]$. In particular, the theory considers that by improving the territory, and therefore the opportunities that that context offers, the lives of its residents will improve. However, despite the efforts to implement such policies, no evidence has been provided for their results, let alone for the evaluation of the impact of these plans on the context and the lives of citizens.

Next, a review of the literature on the gaps and challenges in assessing the impact of integrated area policies on essential retail is presented. In turn, the characteristics of vulnerable areas with regard to the types of essential retail are analyzed as well as the need to take into account the possible contextual differences that may influence the implementation strategies of the developed plans.

\subsection{Integrated Policies in Vulnerable Areas: Evaluation of Their Effects on Retail}

Urban areas have been an important focus in the analysis of economic, social, and cultural development, as these are where important processes of development and social cohesion take place. In addition, these areas often set the stage for situations that lead to processes of segregation, social inequality, and exclusion. Integrated policies are thus developed for more vulnerable places that require intervention. These policies target specific urban areas in a bid to correct territorial imbalances, with the aim of redressing inequalities between such areas [4].

These intervention processes have been developed since the 1950s over different phases. These initially comprised the revitalization and reconstruction of urban centers [6], progressing to focus on the revitalization of disadvantaged neighborhoods in the 1970s and 1980s—seeking to improve "vital opportunities" for residents [7]—and the revaluation of urban space through the idea of entrepreneurship and urban competitiveness in the search to attract economic development after the 1980s [8]. More recently, since the beginning of the twenty-first century, practices focusing on the integrated urban development of areas are being implemented through the participation of "more pluralistic coalitions," aiming to include very diverse stakeholders: both at different governmental levels and from different sectors of action $[3,4,9]$. These diverse actors include the communities and networks that directly or indirectly participate in the development of policies to promote habitable and sustainable neighborhoods [10]. Therefore, through more-integrative approaches (aimed primarily at residents and with the main objectives of community and civic development), the different strategies toward which urban regeneration policies orient their actions manage to identify the policies with more productive approaches. In these policies, the objective is precisely the economic development of the environment and the attraction of visitors or new residents [10,11].

In all cases, these are policies that are aimed at specific urban areas that are hotspots for various kinds of problems and with high levels of socio-spatial vulnerability that generate a negative effect for their residents or other stakeholders carrying out activities there. In relevant the literature, this has been termed the "neighborhood effect" [3]. Therefore, the term "urban vulnerability" not only refers to the composition or socio-economic level of urban areas, but also to the characteristics of the structure of opportunities available to residents (such as access to goods and services, public facilities, healthy spaces, etc.) $[12,13]$.

Nevertheless, despite these policies being widely used in recent decades, there is still no consensus on how to measure the benefits of such programs or how to gather more evidence about their effects $[14,15]$. These types of policies are usually evaluated by means of intensive case studies, conducting interviews with experts or the stakeholders involved, or through specific indicators in relation to the objectives set [5]. As Bailey [16] argues, "the debate has therefore moved on from simply evaluating case studies to exploring the variety of rationalities that best explain the way power is used and exploited by stakeholders in different public policy arenas" [16] p. 317. Some studies, such as Hartmann and Jehling [17] or Shabab et al. [18], show that it is the different strategies underlying the development of 
these policies that promote different spatially distributed economic goods and give rise to different types of cities $[17,18]$. This implies that the empowerment of the communities involved in the plans requires a thorough analysis of the mechanisms and strategies adopted in each plan as well as an analysis of each stakeholder's reaction [16].

Despite the progress that has been made, there is an important research gap with regard to approaching evaluation from a top-down perspective. It is uncommon to find literature detailing the effort involved in including a generalized system for evaluating the effects of implemented plans in relation to the objectives set out in their design. This is shown, for example, in a review of the literature on the evaluation of area-based economic initiatives (ABIs) implemented by the What Works Centre for Local Economic Growth. In this review, only 58 studies out of the more than 2100 included have high quality methodological criteria and focus on evaluating the impact of the policies rather than their process $[19,20]$.

As a result of this discussion, demands have been made in recent years for greater consensus on how to evaluate the outcome of these policies and their effects. For example, by including evaluative proposals in the design of the programs [21] or by obtaining more-detailed data that would improve the measurement of policy effects over time [22]. However, conceptual and methodological problems have constrained studies on the precise effects of these regeneration activities [22]. These obstacles range from an inadequate understanding or insufficient development of the theory underlying political intervention to the chosen evaluation method or a lack of information about the intended impact of the interventions [14]. More specifically, the latter line of analysis concerning the impact of interventions includes several methodological challenges and constraints that will be addressed here, such as the selection of areas for comparison and the appropriate technique for impact measurement or comparison over time $[5,23,24]$.

Some previous studies have taken on these challenges. For example, Mohan, Longo, and Kee [25] or Zapata [26], who-using a longitudinal design - measured the impact of area-based policies on health, and Schulze and Wong [27], who measured the impact of plans in terms of changes in housing markets, residential density, or population growth. With regard to the results, other studies in the U.S., such as Oakley and Tsao [28], Bondonio and Engberg [29], or Smith [30], show us that these programs have no impact on enterprise zones and local employment. Other researchers, such as Pellegrini, Terribile, Tarola, Muccigrosso, and Busillo [31] or Puigcerver-Penalver [32] show a positive impact of EU Regional Policy on economic growth.

The current article will address these challenges, while measuring the impacts of area-based policies in Andalusia on the quality of life of the community in which they are developed. This region has continuously made a great effort in the implementation of this type of policy, actually being a pioneer in the development of some of the programs, yet the same amount of effort has not been made to evaluate their effects. Here, the analysis of these efforts is framed within three types of programs: (a) Rehabilitation Areas (ARB), (b) Areas with Social Transformation Needs (ZNTS), and (c) the URBANA Initiative. These are addressed because although a priori they pursue diverse objectives, in all of them, weak economic activity in an area has been identified as a problem more or less explicitly. In fact, 62 percent of the total number of the projects analyzed explicitly mention the need for measures aimed at economic promotion in the area [4]. The current study focuses specifically on analyzing the possible changes that urban regeneration policies have brought to retail trade in these areas.

\subsubsection{Essential Retail in Vulnerable Areas}

As well as being an important strategic and economic sector in the Spanish economy, retail trade has important implications for cities, especially because of its ability to attract and bring together other activities and services [33-35]. Since the 1990s, the massive growth of retail companies and their global reach has consolidated retail markets around the world, and groups of large companies that promote this reach have emerged [36]. 
Not only does retail transform and model the cities or neighborhoods where it is located, but it is also part of the urban practices and social interactions in these places. As Glaeser, Kolko, and Saiz [33] point out, it is through retail that cities move from places of production to places of consumption. Moreover, the focus and orientation of the types of shops we find in a particular area will result in a particular "atmosphere," an environment, or ultimately, a "cultural scene" that will lead to specific cultural practices and lifestyles or will be targeted at specific social groups. In other words, certain types of businesses give a symbolic character to an area: for example, with a more innovative orientation (through spaces for art, creativity, advertising, photography, etc.) or with other types of businesses that give a territory a more community-driven character and therefore will be directed toward meeting the population's most basic needs (food, personal care, hygiene, etc.) $[35,37,38]$. Hence, understanding both the quantity and composition of economic activity in an area is relevant when designing interventions aimed at stimulating business development and employment growth, particularly in lower-income urban neighborhoods [39].

Many of the actions are directed toward economic promotion or to directly improving the structure of opportunity within a neighborhood by revitalizing its physical environment and thus increasing the opportunities available to residents. In other words, the interventions aim to improve the socio-economic development of an area and are mainly directed at commercial sectors that boost the economy or at improving the access to and promotion of local retail businesses. It is accordingly necessary to analyze the functioning of local commerce: specifically retail businesses that focus on meeting the most basic needs of local residents. This is in line with, for example, studies related to the effects of commodity shortages such as "food deserts" or "food poverty" [40]. These types of goods—and the universal access to them-are fundamental, especially in neighborhoods where mobility to other areas of the city could be seen as an obstacle or difficulty for the residents. Hence, the importance of paying attention to all of the businesses that supply basic elements in the daily lives of citizens, such as shops that provide access to basic and essential goods.

We focus accordingly on measuring the opportunities to access what we term as "essential retailers" or "essential shops." In other words, retailers that focus on providing basic and domestic goods and services to which any citizen-regardless of other factors (ethnic background, socio-economic level, etc.) - needs to have access. The presence of these businesses means "bringing" opportunities for consumption and therefore access to these goods to residents. This consequently improves the opportunities that residents have while also bearing in mind the possible barriers to mobility and access to other areas that are often characteristic of vulnerable areas.

Another aspect to be taken into account is the diversity that exists in the supply of these services, that is, in the sub-sectors of essential retail. In fact, previous findings suggest that in lower income neighborhoods, in addition to having a lower density of commercial establishments, they also have less diversity among these commercial subsectors [39,41]. In this regard, various studies since the 1990s, such as Alwitt and Donley [42] or Powell et al. [43], show that neighborhoods subject to greater economic constraints have the highest levels of vulnerability and the lowest degree of access to services and resources. This is understood as a limitation to the availability of opportunities and therefore is an obstacle or barrier that will affect residents of these neighborhoods in terms of more limited offers (therefore making them more vulnerable). This, in turn, means they will have to travel further in order to enjoy the same services as residents of other neighborhoods.

\subsubsection{Contextual Difference in Retail Business Analysis}

The literature produced in Anglo-Saxon contexts in the 1990s highlights the effects of implementing integrated, area-based intervention policies in cities such as Birmingham, Manchester, and Cardiff. Among the actions contemplated by these interventions were the creation and incentivization of shopping centers or malls as well as convention centers, sports facilities, etc. In general, these types of measures become important tools of 
consensus between public and private actors in the search for local development $[8,44-47]$. This, in itself, provides an incentive for their implementation. Meanwhile, in Spain during the period in question, the retail trade began to decline in many cities, mainly due to the appearance of these large shopping centers in addition to other factors such as changes in consumption habits, greater mobility, etc. [48].

Such actions involve particular features when implemented in areas where revitalization is in turn accompanied using historical buildings, cultural heritage, etc., more typical of the historic districts of large cities. By comparison, there are different aspects when the focus is solely on the development of shopping centers and malls in the outskirts of a city, as this can in turn revitalize the economically depressed areas of these neighborhoods $[47,49,50]$. In fact, many cities in Europe in recent years (Leeds, Rotterdam, Bologna, etc.) have laid the foundations for regeneration in the return of traditional commercial activity to the urban center [51]. Moreover, the fact that-in any type of context-retail trade injects personality, image, and vitality to an area is also extensible, with the loss of commercial activity being one of the most significant indicators of decline in urban centers [48,52]. It is therefore well known that the outcome of regeneration policies in each targeted area will largely be related to the different types of actions and measures, that is, projects that have been developed. However (and the aspect we mainly want to explore in greater depth), outcomes will also relate to the known differences between the different types of intervention contexts. In other words, we assume that the same project will not achieve the same result if applied in different contexts $[4,53]$. In this regard, some empirical studies analyze historic districts of large cities and/or peripheral neighborhoods [54], but little is known about the possible differences between interventions in large cities and interventions in medium-sized cities or towns. Further, there is very little research that analyzes the challenges faced by retail businesses in medium-sized cities and towns in detail [48].

Hence the interest in understanding the effects of urban regeneration projects according to the initial context. That is, controlling for the size of the town or city on the one hand-differentiating between large cities (more than 100,000 inhabitants) and mediumsized cities and towns-and on the other hand, the centrality of the context in terms of the differences attributed to urban centers and neighborhoods on the outskirts. Particularly, we seek to ascertain the impact that integrated policies could have on retail business in a given area in the current study. To this end, it is essential to contextualize the area in relation to the whole of a town or city, which would inform us about the various city dynamics that can affect what happens in those areas. In other words, we want to explore the relationship between the neighborhood and its city. This will help us to differentiate and control for the starting conditions for each area for the purposes of analysis. Furthermore, urban change is often a complex phenomenon to grasp. Above all, it takes place over long periods of time, meaning it is thus sensible to allow a prudent amount of time between intervention and analysis in order to analyze possible changes due to urban policy intervention. In addition, evidence of substantive changes in cities and neighborhoods in the medium and long term is extremely complex, as most of the existing differences are maintained over time $[4,55,56]$. The few evaluative analyses that have been conducted on these processes show that the effects are relatively modest $[4]$ p. 50, [57,58].

In the current paper, we are interested in focusing on the socio-economic promotion of neighborhoods targeted by integrated urban regeneration policies, and more specifically, on the impact that these actions could have on retail businesses as an opportunity structure in an area over a decade. Analyzing both the density and diversity of these businesses will show us the barriers or obstacles that residents of certain more vulnerable areas may find in their immediate surroundings, and above all, whether the integrated actions that target these areas actually modify and improve the situation. To evaluate the effects, we propose the use of a methodology to measure the overall effects of these plans as well as to differentiate them in the different city dynamics. Accordingly, the main hypotheses in this study are: 
Hypothesis 1(H1): The impact of integrated interventions in a specific urban area will improve retail business in the neighborhood by first, increasing the density of basic retail businesses per inhabitant (H1.2) and second, by increasing the diversity in the supply of these basic retail businesses (H1.2);

Hypothesis 2(H2): The impact of these interventions will vary depending on the type of context (historic districts of large cities, historic districts of medium sized towns or cities, or neighborhoods in the outskirts) where the intervention is carried out. In turn, these variations will differ depending on the density of previous businesses in each type of context (H2.1) and the diversity of these businesses (H2.2).

\section{Materials and Methods}

To try to provide some evidence on the impact that interventions over recent decades in Andalusian cities might have had on retail trade, a quasi-experimental design was used. The design defines both "experimental areas" (those targeted by one of the urban regeneration programs analyzed) and their "equivalent areas," also known as control areas. Therefore, we decided to conduct a controlled selection and comparison of "similar pairs"; in other words, areas with the same starting conditions but that differ in terms of whether area-based policies have been implemented (see Figure 1). For our purposes, the areas defined within the framework of the RUCOSA (this research uses the data and methodology of the RUCOSA project (Urban Regeneration and Social Cohesion in Andalusia: towards an evaluative analysis), funded by the I + D framework of the Department of HousingGovernment of Andalusia and the ERDF-European Union.) are used. The experimental areas are defined by aggregating the census tracts subject to intervention (with information obtained from the official documentation for each project). For each experimental area, an equivalent area is located in the same city. The equivalent area needed to meet the following requirements: (a) belong to the same quintile of the municipal urban inequality indicator; (b) have the same population size (around $\pm 50 \%$ of the size of the experimental area); and (c) have a similar urban morphology. The descriptive statistics show that our areas have similar characteristics in terms of the population size and the urban inequality index at a municipal level (see Table S1) (To establish these similarities, we used information from the Urban Vulnerability Atlas compiled by the Ministry of Development for the year 2001, specifically through its Municipal Urban Inequality Indices.) This type of design allows us to understand what would have happened without the effect of the intervention. In other words, the equivalent areas would provide the "counterfactual" conditions necessary to demonstrate the impact of the intervention in the neighborhoods [59].

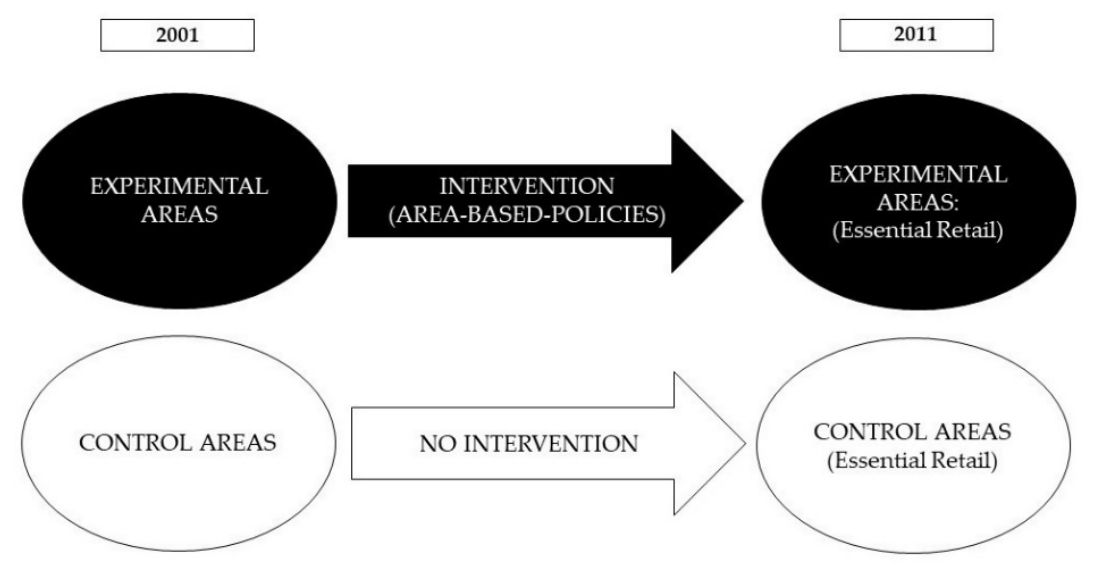

Figure 1. Logic of the quasi-experimental design applied. 
This study considers territorial areas in which at least one project has been implemented within the ARB, ZNTS, and URBAN programs. As explained earlier, these programs have been running since the 1990s and for at least two decades in Andalusia. The impact they may have had on the urban structure for change throughout 2001-2011 will be measured, giving a sufficient period over which to visualize effects in the targeted areas. However, we should not ignore the fact that in the last few years of the period, there was an economic crisis that, in general, hit all of the analyzed areas and thus the retail businesses in those areas. We assume that the effect of the crisis has been equivalent for all of the territories, which is no less relevant, but a priori should not introduce any bias into the analyses and results provided below.

In the analyses, intervention is our independent variable; that is, whether the territorial area was subject to one or more urban regeneration projects (experimental/control). This gives a total of 60 pilot areas located in the municipalities where urban regeneration projects (ARB, ZNTS, and URBAN) have been implemented in recent decades as well as 60 other areas (their equivalents) that meet previously defined requirements (the same starting conditions) and where no public intervention of this type has been developed. (Out of a set of 134 areas (67 experimental and 67 equivalents) some "extreme cases" were identified. These were excluded, resulting in conducting the analysis on a total of 120 cases.) The phenomenon analyzed here is essential retail trade; that is, retail trade focused on providing basic and domestic goods and services that any citizen should be able to access. To proceed, we will explore the diverse range of shops available that we select and group according to the National Classification of Economic Activities (CNAE) to four digits of disaggregation. (Shown in Appendix A). More specifically, the analysis incorporates two dependent variables: on the one hand, the density of essential retail business, and on the other hand, its diversity. The first is measured using a ratio that gives the number of businesses per 1000 inhabitants. This was calculated by taking into account all the sectors analyzed together as well as each of the subgroups detected. Our second dependent variable (which refers to the concentration according to the basic services offered in a neighborhood) was measured through the Herfindahl-Hirschman index, an indicator that shows us the degree of market concentration. The Herfindahl index is calculated according to the following equation:

$$
I H H=\sum_{i=1}^{n} s_{i}^{2}
$$

where $s$ is the proportion of businesses of category, $i$ for each trade retail sector. In order to calculate this, we obtained the market share of each subgroup in the area to see how much of the market is concentrated there. A greater degree of diversity increases a neighborhood's capacity to offer access to a wider range of commodities, while homogeneity or concentration would limit commercial access to a smaller range of products and/or services for residents. This indicator ranges from 0 to 1 , with lower values indicating greater diversity in relation to the retail subtypes in the analyzed areas and values close to 1 showing greater concentration or homogeneity in the market offered.

In general terms, we intend to show how intervention strategies (developed within the framework of the selected plans and programs) have some kind of effect, first of all, on the density of retail business opportunities with respect to the basic needs of the consumer. For the second aspect, we examine the diversity in the types of goods that can be accessed through the same retail businesses. That is, we measure the likelihood of having greater or lesser access to various types of essential goods, such as supermarkets, pharmacies, textile shops, etc. 
To describe the changes in the analyzed areas, we first examined absolute variancethat is, the change from 2001 to 2011 (to see the general trend) - and relative variance (the growth rate), allowing us to analyze change based on its starting point. The growth rate is expressed as the difference between two values over time in terms of a percentage of the first value.

$$
\text { Growth rate }=\left[\left(Y_{t}-Y_{t-n}\right) / Y_{t-n}\right] \times 100
$$

where $Y_{t}$ is the present value (2011), and $Y_{t-n}$ is the past value (2001). However, in order to ascertain the change that is attributed precisely to the intervention of the projects, the Difference in Differences (DiD) method is used through the application of variance analysis. This will show the "average impact" of the projects for each indicator [60].

$$
\operatorname{DiD}=\left[\mathrm{Y}_{1}\left(\mathrm{t}_{2}\right)-\mathrm{Y}_{1}\left(\mathrm{t}_{1}\right)\right]-\left[\mathrm{Y}_{0}\left(\mathrm{t}_{2}\right)-\mathrm{Y}_{0}\left(\mathrm{t}_{1}\right)\right]
$$

where:

$Y_{1}\left(t_{1}\right)=$ the result observed in the period 2001 in the experimental areas;

$\mathrm{Y}_{1}\left(\mathrm{t}_{2}\right)=$ the result observed in the period 2011 in the experimental areas;

$\mathrm{Y}_{0}\left(\mathrm{t}_{1}\right)=$ the result observed in the period 2001 in the control areas;

$\mathrm{Y}_{0}\left(\mathrm{t}_{1}\right)=$ the result observed in the period 2011 in the control areas.

This technique, one among the alternative methods of evaluation for non-experimental data according to Blundell and Costa [61] p. 437, "can provide a more robust estimate of the impact of the treatment." Furthermore, its use is possible because we have repeated cross-sectional information available (prior to the intervention as well as one decade later). This allows us to systematically and extensively compare the results related to policy objectives between areas that have been the subject of regeneration and those that have not [26]. This will show the difference between the changes over time in the experimental areas and the changes over time in the control areas, allowing us to compare the two groups and understand the effects that are attributable to the projects. In addition, change trends are analyzed using repeat measurement models for each calculated indicator and in the different examined contexts. This will translate into understanding the extent to which the area-based public interventions implemented in Andalusia in recent decades have served essential retail businesses as a fundamental element in reducing urban vulnerability. It will also illustrate the need to take this into account when analyzing the structure of opportunity and basic resources of an individual. Therefore, the possible changes that have taken place will be analyzed first in order to focus on the extent to which these changes are due to the impact of the initiatives that have been carried out.

\section{Results}

An initial descriptive examination of the two indicators (the density and diversity of retail business) for the period 2001-2011 shows, with regard to the density of local retail business in general, an absolute increase of close to 5 points. This is equivalent to a relative variance of 127.74 percent. In absolute terms, the increase is greater in the equivalent areas, but in relative terms-that is, taking into account the starting conditions of both (initial value) - the experimental areas show the greatest increase. With regard to the concentration indicator, it illustrates a general trend toward heterogeneity in the types of retail businesses; that is, greater diversity in the residents' access to different products and/or services. Further, we see that both absolute and relative variance are similar in the experimental and equivalent areas (a 16.56 percent decrease in experimental areas versus a 20 percent decrease in control areas) (see Table 1). 
Table 1. Absolute and relative variance in retail business (density and diversity). Descriptive statistics.

\begin{tabular}{|c|c|c|c|c|c|}
\hline & & 2001 & 2011 & $\begin{array}{l}\text { 2011-2001 } \\
\text { (Absolute } \\
\text { Variance) }\end{array}$ & $\begin{array}{c}\text { Relative } \\
\text { Variance Rate }\end{array}$ \\
\hline & & Mean (SD) & Mean (SD) & Mean (SD) & Per. (\%) \\
\hline \multirow{3}{*}{$\begin{array}{l}\text { Total trade } \\
\text { density }\end{array}$} & \multirow{3}{*}{$\begin{array}{c}\text { Control areas } \\
\text { Experimental } \\
\text { areas } \\
\text { Total }\end{array}$} & $4.60(8.55)$ & 10.25 (17.41) & $5.64(9.11)$ & 122.57 \\
\hline & & $2.81(2.53)$ & $6.64(6.86)$ & 3.83 (4.55) & 136.21 \\
\hline & & $3.71(6.35)$ & $8.44(13.31)$ & $4.74(7.23)$ & 127.74 \\
\hline \multirow{3}{*}{$\begin{array}{l}\text { Concentration } \\
\text { Indicator(IHH) }\end{array}$} & \multirow{3}{*}{$\begin{array}{c}\text { Control areas } \\
\text { Experimental } \\
\text { areas } \\
\text { Total }\end{array}$} & $0.34(0.19)$ & $0.27(0.07)$ & $-0.05(0.16)$ & -20.17 \\
\hline & & $0.41(0.027)$ & $0.34(0.17)$ & $-0.05(0.21)$ & -16.56 \\
\hline & & $0.38(0.22)$ & $0.31(0.13)$ & $-0.05(0.19)$ & -18.01 \\
\hline
\end{tabular}

Italic font: $p$-value $<0.10$; Italic and bold font: $p$-value $<0.05$

Can this change be attributed to the effect of the urban regeneration projects? What we are mainly interested in seeing is if there is any effect of the policies on the analyzed indicators. If this is the case, we will obtain a positive value when there has been either an increase in the businesses analyzed or a change in the diversity indicator in favor of the experimental areas (target areas for intervention). If the value is equal (or very close) to zero, it would mean that the projects have had no clear effect (there are no differences in the trend toward change over time between experimental and equivalent neighborhoods). Table 2 shows the effect of the programs in each of the analyzed commercial sectors as well as the diversity of these sectors in the targeted area. We cannot generally attribute the effects of the interventions in the analyzed subsectors in the experimental areas. In fact, only in the case of food shops is there a small positive effect, whereas in the other sectors (textiles, household goods, care, etc.), not only has there not been an increase in the case of the targeted areas, but the difference is actually favorable to the control or equivalent areas; that is, it seems they have followed different trends. Although there is no specific database of studies to enable comparison with previous findings, these results would be in line with other studies that show a very low impact of urban regeneration plans on employment growth or the number of companies in the areas targeted by intervention [26,62]. However, these same interventions have shown effects in other areas, such as habitability or education [4], or more specific aspects, such as preventable mortality [26] or participation in associations [63]

Table 2. The impact of area-based policies on retail business. Difference in Differences Technique (DiD).

\begin{tabular}{|c|c|c|c|c|}
\hline & & $\begin{array}{c}\text { Experimental } \\
2011-2001\end{array}$ & $\begin{array}{c}\text { Control } \\
2011-2001\end{array}$ & $\begin{array}{l}\text { Difference in } \\
\text { Differences }\end{array}$ \\
\hline \multirow{8}{*}{ Density } & General retail trade & 3.8299 & 5.6427 & -1.8128 \\
\hline & Food shops & 0.5134 & 0.4959 & 0.0175 \\
\hline & Textiles shops & 0.7115 & 1.1655 & -0.454 \\
\hline & $\begin{array}{l}\text { Pharmacies and } \\
\text { medical products }\end{array}$ & 0.0409 & 0.0755 & -0.0346 \\
\hline & Care & 0.4678 & 0.7589 & -0.2911 \\
\hline & $\begin{array}{c}\text { Prepared meals and } \\
\text { beverages }\end{array}$ & 1.6977 & 2.4865 & -0.7888 \\
\hline & Stationers & 0.1649 & 0.2065 & -0.0416 \\
\hline & Household goods & 0.2338 & 0.4537 & -0.2199 \\
\hline $\begin{array}{l}\text { Concentration } \\
\text { (IHH) }\end{array}$ & Index & -0.0682 & -0.0695 & 0.0013 \\
\hline
\end{tabular}

As highlighted in previous literature, however, it is necessary to control for possible the contextual effects on these results. In order to do this, we compared the change trends in the experimental and control areas with regard to the density and diversity of businesses, but on this occasion, we controlled for the possible effect of different contexts (the effect 
of interventions in the historic districts of large cities, medium-sized towns and cities, or neighborhoods on the outskirts) (see Table 3).

Table 3. The impact of area-based policies on "essential shops." Contextual differences.

\begin{tabular}{|c|c|c|c|c|c|c|}
\hline & \multicolumn{3}{|c|}{ Density } & \multicolumn{3}{|c|}{ Diversity (IHH) } \\
\hline & \multicolumn{2}{|c|}{ Historic District } & \multirow{2}{*}{$\begin{array}{c}\text { Neighborhoods } \\
\text { on the } \\
\text { Outskirts }\end{array}$} & \multicolumn{2}{|c|}{ Historic District } & \multirow{2}{*}{$\begin{array}{c}\text { Neighborhoods } \\
\text { on the } \\
\text { Outskirts }\end{array}$} \\
\hline & $\begin{array}{l}\text { Large } \\
\text { Cities }\end{array}$ & $\begin{array}{l}\text { Medium } \\
\text { Cities }\end{array}$ & & $\begin{array}{l}\text { Large } \\
\text { Cities }\end{array}$ & $\begin{array}{l}\text { Medium } \\
\text { Cities }\end{array}$ & \\
\hline & $\begin{array}{l}\text { Mean } \\
\text { (SD) }\end{array}$ & $\begin{array}{l}\text { Mean } \\
\text { (SD) }\end{array}$ & Mean (SD) & $\begin{array}{l}\text { Mean } \\
\text { (SD) }\end{array}$ & $\begin{array}{l}\text { Mean } \\
\text { (SD) }\end{array}$ & Mean (SD) \\
\hline $\begin{array}{l}\text { Experimental: } \\
\text { difference } \\
\text { 2011-2001 }\end{array}$ & $7.40(4.80)$ & $6.17(5.66)$ & $1.75(2.30)$ & $0.02(0.03)$ & $\begin{array}{l}-0.01 \\
(0.13)\end{array}$ & $-0.10(0.26)$ \\
\hline $\begin{array}{l}\text { Control: } \\
\text { difference } \\
\text { 2011-2001 }\end{array}$ & $\begin{array}{c}14.97 \\
(18.13)\end{array}$ & $5.35(5.13)$ & $3.14(3.84)$ & $\begin{array}{l}-0.01 \\
(0.06)\end{array}$ & $\begin{array}{l}-0.08 \\
(0.21)\end{array}$ & $-0.06(0.17)$ \\
\hline Total & $\begin{array}{c}11.18 \\
(13.56)\end{array}$ & $5.76(5.35)$ & $2.44(3.23)$ & $0.06(0.05)$ & $\begin{array}{l}-0.04 \\
(0.17)\end{array}$ & $-0.08(0.22)$ \\
\hline $\begin{array}{l}\text { Difference in } \\
\text { Differences } \\
\text { (DiD) }\end{array}$ & -7.57 & 0.82 & -1.39 & 0.03 & 0.07 & -0.04 \\
\hline $\mathrm{N}$ & 20 & 36 & 78 & 20 & 33 & 71 \\
\hline
\end{tabular}

In the table, we can see the differences between experimental areas and control areas for both density and the diversity index in the three analyzed contexts. We can broadly conclude that the effects that appear to result from program intervention are small, but there are some observable trends that could shed light with reasonable clarity on the impact of these programs.

First, with regard to analyzing the density of retail business, we found that in general, the equivalent areas have a higher density, both before and after intervention. However, the trend is different between the historic districts of large cities and those of medium-sized towns and cities. In large cities, the equivalent areas show a greater increase in density and a noticeable difference from experimental areas $(\mathrm{DiD}=-7.57)$. In fact, this negative difference shows that there has been no effect in the experimental areas, or to put it another way, the increase in the equivalent areas was greater in the analyzed period. The same is true for neighborhoods located on the outskirts, where the increase is evident in the control areas (also with significant differences: $p$ value $<0.05$ ), meaning that there is no observable effect for the intervention in the experimental areas. However, the trend changes when we analyze it for the historic districts of medium-sized towns and cities. In this case, the direction of the difference, albeit at low levels (Did =0.82), is positive. This indicates that the change, although slight, is toward a higher density of retail business in the experimental areas.

With regard to the analysis of market concentration or diversity (measured through the Herfindahl index), we know that negative values in both the experimental and equivalent areas would show a downward trend for the indicator, which would mean greater diversity in the retail sectors available in an area. However, the trend toward a greater diversity of sectors is only seen in the experimental neighborhoods on the outskirts, where we find a slight decrease in the index $(\mathrm{DiD}=-0.04)$. In historic districts, by comparison, this same pattern does not appear. In fact, in such districts in large cities, we can see greater homogeneity between the analyzed retail sectors, which might indicate increased specialization in the supply of some types of businesses. In the historic districts of smaller cities and towns, there is no attributable effect to the intervention, since the trend in the equivalent areas is much greater when examining market diversity, while experimental areas show little variation in this regard $(\mathrm{DiD}=0.03)$. Figure 2 shows the average marginal estimates for each indicator in different contexts. 


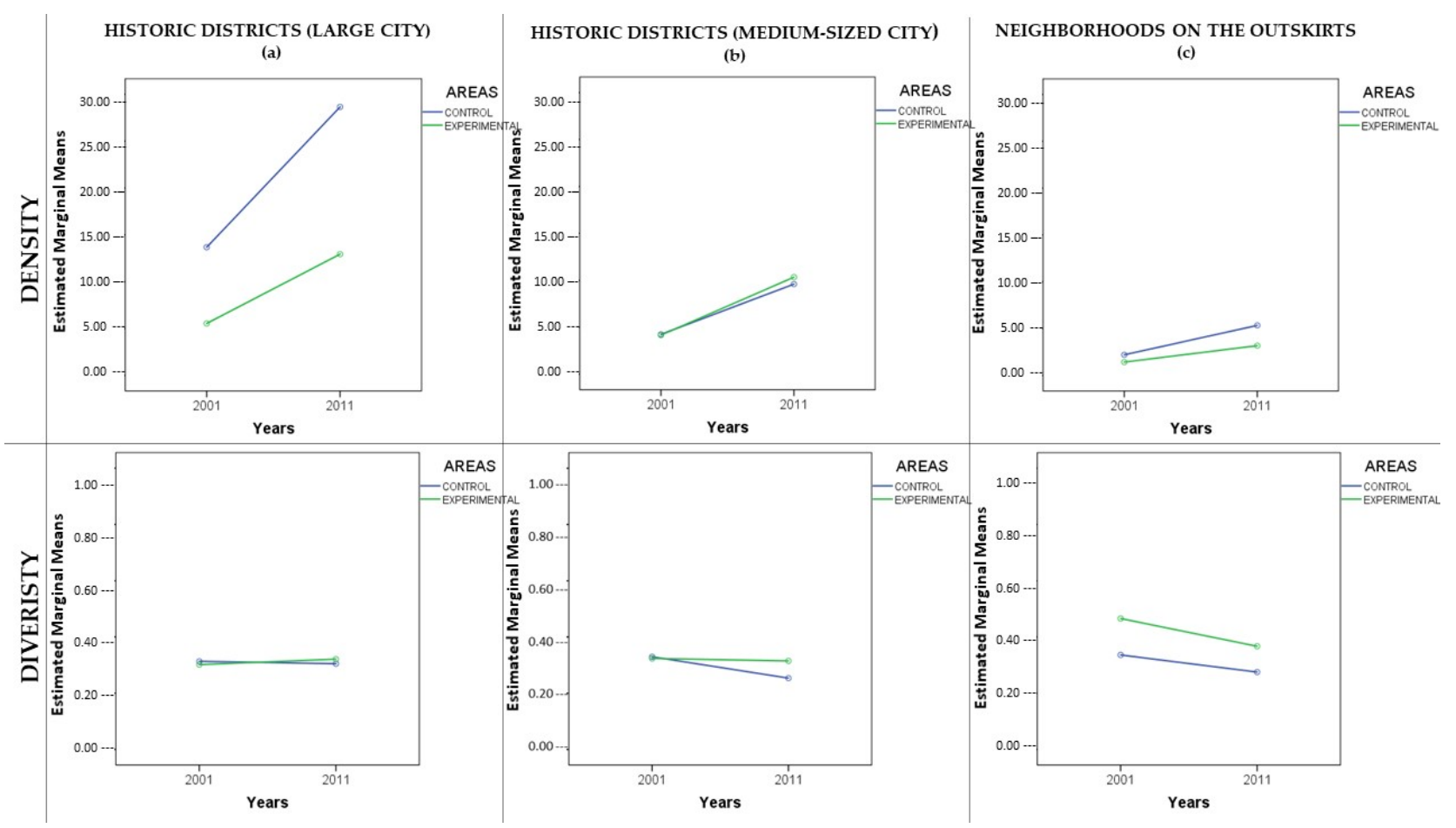

Figure 2. Orientation of the impact of area-based policies on "essential shops." Estimated marginal averages per repeat measurements model: (a) Historic District Large City; (b) Historic District Medium-Size City; (c) Neighborhoods on the Outskirts.

\section{Discussion}

Measuring the impact that urban regeneration plans have on the quality of life of the community in which they are developed is a fundamental field of study for the good design and effectiveness of public policies. The aim of the current work is therefore to contribute to the measurement of the impact that urban regeneration plans (ARB, ZNTS, and URBAN) have had in the areas where they have been implemented in Andalusia in recent decades. In addition, we focused on a key indicator of the economic development of the area: essential retail businesses. This work thus mainly contributes to the field of urban policy studies: on the one hand, by providing a design to evaluate the effects of public intervention in plans where it was previously not common, and on the other hand, by emphasizing the analysis of a phenomenon (essential retail) that has not been the focus before. This is an attempt to deal with one of the main weaknesses detected in this field of study: the lack of previous evaluations of the impact of public policies applied to specific areas.

A review of the scientific literature shows that although such policies aimed at addressing social problems in specific areas are very popular in many countries, studies assessing their impact are limited. The systematic review conducted by the What Work Centre for local economic growth includes all studies that have evaluated the impact of the EU Cohesion Policy [19] and the impact of Enterprise Zones and other economic area based initiatives [20] from the UK and other OECD countries. In this review, only 58 studies are identified that meet the quality standards (out of more than 2100 policy evaluations and evidence reviews). Moreover, in our review of the impact of these schemes on essential retail, we have not found any work that explicitly mentions this phenomenon. There is, however, work evaluating similar aspects, such as the effect on shopping areas [47], measuring the impact of measures to promote enterprise zones [23], or specifically, on healthier types of retail food $[25,26,39-43]$. 
The current work has justified the importance of having access to this type of trade, especially in vulnerable areas, in order to provide a greater structure of opportunities to areas that normally present more barriers and obstacles to accessing basic and essential goods for the daily lives of residents [14]. This is why the research gap that has been detected should be taken into account in future analyses and lines of research. Furthermore, the literature on the evaluation of impact measurement does not present a general consensus on the guidelines that should be followed or the most suitable guidelines [14]. Accordingly, here we propose an approach to this phenomenon through a simple analysis, the $\mathrm{DiD}$, but generalized and supported by studies of scientific quality in these fields $[19,20]$.

As reflected in the results of the study, there does not seem to be a positive outcome of the urban regeneration plans with regard to retail business. This does not support our hypothesis H1. This result is in line with other studies that have reached the same conclusion: that there is no, or little, effect of these policies in specific areas $[14,15,22]$. However, we could suggest some limitations that affect this study's internal validity. With regard to the use of the proposed indicators, we find that access to the results of small-scale disaggregated secondary data presents a great difficulty for neighborhood studies. Data on the number of employees, type of trade, and more specificities would improve the measurement of the analyzed phenomenon. With regard to external validity, this is a study applied to the region of Andalusia. We cannot generalize it to other regions or to other programs, since in this case, we are focusing on the framework of three specific programs (ARB, ZNTS and URBAN) that have only been applied in this territory. However, we could argue that in areas where implemented programs follow the same logic and where implementation follows the same vulnerability criteria, everything points to the suggestion that effects of these policies cannot influence the presence and diversity of basic facilities in a specific area.

Nevertheless, in line with our second hypothesis $\mathrm{H} 2$, the obtained results do point to possible changes in the trend as a function of factors other than the intervention carried out: specifically, the type of context. Although no significant effects are shown, there are small trends related to the type of context in which the policies are applied. In the same way, the results do not show significant differences that endorse the internal validity or support a causal relationship. However, as these plans are evaluated in a limited population and slight changes in trends are observed in relation to their context, we can confirm a necessary line of work for the evaluation of urban policies, or at least the suggestion that contextual information should be introduced in the planning, analysis, and evaluation of these programs.

We consider that the obtained results allow us to conclude that the impact of these plans can be conditioned by contextual characteristics; that is, the different trends can be explained according to the starting conditions of the territorial context (or neighborhood) in which they are developed. Hence, one of our major contributions is to also highlight the specificity of medium-sized cities and towns in relation to large cities, as well as the specificity of peripheral neighborhoods compared to central areas. Intervention in neighborhoods on the outskirts does not have the same effect as it does in historic districts, but the same is true for the centers of large cities or for smaller towns and cities. In other words, both intra-urban centrality and population size are aspects that promote differentiating dynamics in relation to this type of retail supply. 
The results show, on the one hand, the situation of neighborhoods on the outskirts of towns. Here, although the business density does not increase as expected, the diversity does; that is, there are fewer businesses than expected, but they are more heterogeneous in their opportunities. In other words, greater diversity in the supply of basic goods in a neighborhood will result in greater access to opportunities for residents of the area. On the other hand, urban centers in medium-sized towns and cities show an increased density of retail business, albeit without any significant changes in terms of diversity. Lastly, in the urban centers of large cities, not only are there no observable effects that are attributable to intervention in relation to this type of trade, but we also find that the gap between experimental and equivalent areas becomes even greater. In other words, in terms of the development of these businesses, the equivalent areas show better indicators over time in contrast to the stagnation of urban centers. This empirically supports the thesis put forward by other studies: that revitalization in historic places has a greater impact on the prices of commercial properties. It even improves the economic commercialization of an area and its businesses through obtaining competitive advantages over areas with new residential development projects $[64,65]$. Furthermore, the development of other types of shops and businesses is more common, for example, those geared toward the promotion of heritage, creativity, tourism, etc. [35,37,66-68]. However, smaller cities or medium-sized towns and cities seem to be able to direct their commercial development toward both aspects by accommodating the incorporation of basic core businesses in the area, as already pointed out in the results discussed earlier, as well as businesses based on tourism, creative, and other specialized activities.

Other indicators could nevertheless be introduced to improve this analysis, such as the implementation strategies of each plan, the stakeholders involved, or the integration of other dimensions, such as the environmental policies in the regional plans.

In future research, we should insist on developing impact assessments for these issues, for example, through specific case studies and by more closely analyzing the communities involved in programs developed in recent years. It is also important to incorporate environmental policies in urban and regional regeneration plans for vulnerable areas, with the aim of promoting natural conservation strategies and constituting a commitment to a balanced landscape between green and urban spaces. In the case of vulnerable areas, the incorporation of this perspective would imply an improvement in relation to the sustainability of these areas, complementing the actions aimed at promoting socioeconomic growth. In this sense, it is a priority to incorporate future lines of action and study in the regeneration plans of vulnerable areas that support this perspective from different points of view: political (institutional support), guidance (cultural interventions that promote proactive individual behaviors), and educational (educational activities that promote respect for the environment in all areas [69].

In this way, we would also allow policymakers and technical staff to evaluate and target their efforts more efficiently, knowing that at the very least, the particularities of the areas in which urban policies are developed have to be taken into account.

This would be possible by applying qualitative methodological strategies that would allow us to uncover the logic of the stakeholders who are involved [10,16,17], helping us to gain a more in-depth understanding of the dynamics and action strategies that involved in the socioeconomic development of vulnerable areas. Another suggestion would be to establish, by replicating this quasi-experimental design, a comparative analysis between different regions that could enhance understanding of the design and implementation of area-based urban policies. 


\section{Conclusions}

As noted above, the role of "essential retail" is fundamental to facilitate and promote greater economic development and social cohesion among citizens. This is particularly important in areas where factors such as a lack of access to other areas of the city, poor mobility, and greater urban vulnerability contribute to the fact that the area "lived and experienced" by residents is mostly that of where they reside. In this regard, interventions through urban programs and policies aimed directly at promoting greater social cohesion among residents could contribute to changes in the "structure of opportunities" in the neighborhoods where they are implemented.

On the one hand, an increase has been observed in both experimental and control areas with respect to business density. Further, the increase, relatively speaking (in other words, taking into account the starting point of these areas), is even greater in experimental areas. Furthermore, there has also been a general trend toward a greater diversity of retail businesses in the analyzed areas. However, having examined the impact that these policies have had on shaping retail in the area, we found that intervention has generally had no effect. To put it another way, there does not seem to be a framework that marks the logic of intervention toward the structure of opportunity offered by retail business, endowing it with an increased supply or greater diversity of products offered in targeted areas. Therefore, it is not the public interventions channeled through integrated policies that could produce a basic business structure for those residing in more vulnerable areas and who could avoid obstacles in terms of accessing these goods and services, nor do the results support the conclusion that the type of context is a determining factor, but they do show differentiated trends, meaning that we should pay more attention to this in subsequent analyses. On the other hand, medium-sized towns and cities seem more open to this type of commercial development, and residential neighborhoods seem more likely to maintain a diverse offering of opportunities for their residents. The urban centers of large cities in Andalusia require their own analysis.

Supplementary Materials: The following are available online at https:/ / www.mdpi.com/article/10 .3390 / su13148023/s1, Table S1: Validation of experimental and equivalent areas. ANOVA (mean values), Table S2: Absolute and relative variance in retail business (density and diversity) Descriptive statistics.

Author Contributions: Conceptualization, C.M.-M., M.R.H.-G. and C.G.-B.; Data curation, C.M.-M.; Formal analysis, C.M.-M. and C.G.-B.; Funding acquisition, C.M.-M. and M.R.H.-G.; Investigation, C.M.-M., M.R.H.-G. and C.G.-B.; Methodology, C.M.-M., M.R.H.-G. and C.G.-B.; Project administration, C.M.-M. and M.R.H.-G.; Supervision, C.M.-M. and M.R.H.-G.; Validation, C.M.-M., M.R.H.-G. and C.G.-B.; Visualization, C.M.-M. and C.G.-B.; Writing - original draft, C.M.-M., M.R.H.-G. and C.G.-B. All authors have read and agreed to the published version of the manuscript.

Funding: This research was funded by Operational Program European Regional Development Fund (ERDF/FEDER) 2014-2020-(UPO-1264762): Project Civic Participation and Development Community in local social welfare policies in Andalusia. This research uses data from the RUCOSA project (Urban Regeneration and Social Cohesion in Andalusia: towards an evaluative analysis, $\mathrm{n}^{\circ}$ reference: GGI30011/DIY) funded by the I + D framework of the Department of Housing-Government of Andalusia and the ERDF-European Union (ERDF/FEDER).

Institutional Review Board Statement: Not applicable.

Informed Consent Statement: Not applicable.

Data Availability Statement: Restrictions apply to the availability of these data. For more information, please contact the authors.

Acknowledgments: The authors wish to thank the staff and researchers at the Consejería de Fomento y Vivienda of the Junta de Andalucía, and of all its agencies for their work and professionalism in supporting the development of RUCOSA.

Conflicts of Interest: The authors declare no conflict of interest. 


\section{Appendix A}

Table A1. CNAE codes used to calculate essential shops.

\begin{tabular}{lc}
\hline CNAE_5211 & Retail trade: largely food, beverages, and tobacco in non-specialized establishments \\
\hline CNAE_5221 & Retail trade selling fruits and vegetables \\
\hline CNAE_5222 & Retail trade selling meat and meat products \\
\hline CNAE_5223 & Retail trade selling fish and seafood \\
\hline CNAE_5211 & Retail trade: largely selling food, beverages, and tobacco in non-specialized establishments \\
\hline CNAE_5241 & Retail trade selling textiles \\
\hline CNAE_5242 & Retail trade selling clothing \\
\hline CNAE_5243 & Retail trade selling footwear and leather goods \\
\hline CNAE_5231 & Retail trade selling pharmacy products \\
\hline CNAE_5232 & Retail trade selling medical and orthopedic items \\
\hline CNAE_5233 & Retail trade selling cosmetics and toiletries \\
\hline CNAE_9302 & Hairdressers and other beauty treatments \\
\hline CNAE_9304 & Body and health maintenance activities \\
\hline CNAE_5530 & Restaurants \\
\hline CNAE_5540 & Beverage establishments \\
\hline CNAE_5552 & Provision of prepared meals \\
\hline CNAE_5247 & Retail trade selling books, newspapers, and stationery \\
\hline CNAE_5244 & Retail trade selling appliances, radio, television, and audio devices \\
\hline CNAE_5245 & Retail trade selling furniture; lighting fixtures, and other household items \\
\hline
\end{tabular}

\section{References}

1. Porcel, S.; Antón-Alonso, F.; Muñoz, I. Les polítiques de millora de barris a debat. Pap. Regió Metrop. De Barc. Territ. Estratègies Planejament 2020, 63, 10-19.

2. Hernandez, A.; Matesanz-Parellada, Á.; Rodríguez-Suárez, I.; García-Madruga, C. Evolución de las políticas de rehabilitación en Áreas de Rehabilitación Integrada en España (1978-2012). Inf. Construcción 2015, 67, m024. [CrossRef]

3. Navarro, C.J. Políticas de regeneración urbana en España en el marco de las iniciativas de la unión europea. Pap. Regió Metrop. De Barc. Territ. Estratègies Planejament 2021, 63, 69-81.

4. Navarro, C.J.; Echaves-García, A.; Guerrero-Panal, G.; Moya-Alfonso, R.; Mateos-Mora, C.; Rodríguez-García, M.J.; Moya, A.R. Mejorar la Ciudad Transformando Sus Barrios; Centro de Sociología y Políticas Locales-Universidad Pablo de Olavide: Sevilla, Spain, 2016.

5. Navarro, C.J.; Rodriguez-Garcia, M.-J.; Gerrero Mayo, M.J. (Eds.) Lógica e Impactos de la Estrategia Integral en Políticas Urbanas; Icaria: Barcelona, Spain, 2020; p. 172.

6. Logan, J.; Molotch, H. Urban Fortunes the Political Economy of Place; The University of California Press: Berkeley, CA, USA, 1987.

7. $\quad$ Fainstein, N.I.; Fainstein, S.S. Urban Political Movements; Prentice-Hall: London, UK, 1974.

8. Harvey, D. Voodoo cities. New Statesman Soc. 1988, 30, 33-35.

9. Navarro, C.J.; Rodríguez-García, M.J. Model of local governing coalitions: Politics or policy effects? Urban Geogr. 2015, 36, 1149-1168. [CrossRef]

10. Virani, T. Micro-community engagement and area-based regeneration in East London: The case of Chrisp Street Market. City Cult. Soc. 2020, 22, 100345. [CrossRef]

11. Rodriguez, M.J.; Mateos, C.; Navarro, C. Cultural Strategies, Creativity, and Local Development in Spain. In Can Tocqueville Karaoke? Global Contrasts of Citizen Participation the Arts and Development; Clark, T., Ed.; Research in Urban Policy: Bingley, UK, 2014; pp. 121-134.

12. Musterd, S.; Ostendorf, W. Integrated urban renewal in The Netherland: A critical appraisal. Urban Res. Pract. 2008, 1, 78-92. [CrossRef]

13. Fernández, M.; Navarro, C.J.; Zapata-Moya, A.R.; Mateos-Mora, C. El análisis de la desigualdad urbana. Propuesta y validación de un índice de nivel socioeconómico en áreas urbanas españolas (1991-2001). Empiria 2018, 39, 49-77.

14. Rhodes, J.; Tyler, P.; Brennan, A. Assessing the effect of area based initiatives on local area outcomes: Some thoughts based on the national evaluation of the single regeneration budget in England. Urban Stud. 2005, 42, 1919-1946. [CrossRef]

15. Tyler, P.; Warnock, C.; Provins, A.; Lanz, B. Valuing the benefits of urban regeneration. Urban Stud. 2013, 50, 169-190. [CrossRef]

16. Bailey, B. Understanding Community Empowerment in Urban Regeneration and Planning in England: Putting Policy and Practice in Context. Plan. Pract. Res. 2010, 25, 317-332. [CrossRef] 
17. Hartmann, T.; Jehling, M. From Diversity to Justice-Unraveling Pluralistic Rationalities in Urban Design. Cities 2019, 91, 58-63. [CrossRef]

18. Shahab, S.; Hartmann, T.; Jonkman, A. Strategies of municipal land policies: Housing development in Germany, Belgium, and Netherlands. Eur. Plan. Stud. 2021, 29, 1132-1150. [CrossRef]

19. What Works Centre for Local Economic Growth. Evidence Review: Area-based Initiatives: EU Structural \& Cohesion Policies. 2016. Available online: https://whatworksgrowth.org/public/files/Policy_Reviews/16-01-04-Area-based-initiatives-EUProgrammes.pdf (accessed on 14 June 2021).

20. What Works Centre for Local Economic Growth. Evidence Review: Area-Based Initiatives: Enterprise Zones. 2016. Available online: https:// whatworksgrowth.org/public/files/Policy_Reviews/16-01-04-Area-based-initiatives-EZ.pdf (accessed on 14 June 2021).

21. Sauders, M. Capturing effects of interventions, policies and programmes in the European context: A social practice perspective. Evaluation 2011, 17, 89-102. [CrossRef]

22. Evans, G. Measure for Measure: Evaluating the evidence of culture's contribution to regeneration. Urban Stud. 2005, 42, 959-983. [CrossRef]

23. Ploegmakers, H.; Beckers, P. Evaluating urban regeneration: An assesment of the effectiveness of physical regeneration initiatives on run-down industrial sites in the Netherlands. Urban Stud. 2015, 52, 2151-2169. [CrossRef]

24. Robson, B. Area-based politcy evaluatin. In Evaluating Local Economic and Employment Development: How to Assess What Works among Programmes and Policies; Alistair, N., Ging, W., Eds.; Organisation for Economic Co-Operation and Development: Paris, France, 2004; pp. 199-220.

25. Mohan, C.; Longo, A.; Kee, F. Evaluation of the health impact of an urban regeneration politcy: Neighbourhoos Renewal in Northern Ireland. J. Epidemmiol. Community Health 2017, 71, 919-927. [CrossRef] [PubMed]

26. Zapata-Moya, A.R.; Navarro, C.J. Impacto f área regeneration policies: Performing integral interventions, changing opportunity structures and reducig health inequialities. J. Epidemiol. Community Health 2017, 71, 239-247. [CrossRef]

27. Schulze, A.; Wong, C. Brownfield Residential Development: What happens to the most deprived neighbourhoods in England? Urban Stud. 2012, 49, 2989-3008. [CrossRef]

28. Oakley, D.; Tsao, H.S. A New Way of Revitalizing Distressed Urban Communities? Assessing the Impact of the Federal Empowerment Zone Program. J. Urban Aff. 2006, 28, 443-471. [CrossRef]

29. Bondonio, D.; Engberg, J. Enterprise Zones and Local Employment: Evidence from the States Programs. Reg. Sci. Urban Econ. 2000, 30, 519-549. [CrossRef]

30. Smith, R. Empowerment for Whom? The Impact of Community Renewal Tax Incentives on Jobs and Businesses. Urban Stud. 2015, 52, 702-720. [CrossRef]

31. Pellegrini, G.; Terribile, F.; Tarola, O.; Muccigrosso, T.; Busillo, F. Measuring the Effects of European Policy on Economic Growth: A Regression Discontinuity Approach. Pap. Reg. Sci. 2013, 92, 217-233. [CrossRef]

32. Puigcerver-Penalver, M.C. The Impact of Structural Funds Policy on European Regions' growth. A Theoretical and Empirical Approach. Eur. J. Comp. Econ. 2007, 4, 179-208.

33. Glaeser, E.; Kolko, J.; Saiz, A. Consumer city. J. Econ. Geogr. 2001, 1, 27-50. [CrossRef]

34. Zukin, S. Urban Lifestyles: Diversity and Standardisation in Spaces of Consumption. Urban Stud. 1998, 35, 825-839. [CrossRef]

35. Clark, T.N. Urban amentites: Lakes, opera and juice bars do they drive development? In The City as an Entertainment Machine; Clark, T., Ed.; Research in Urban Policy;: Bingley, UK, 2003; Volume 9, pp. 103-140.

36. Lowe, M.; Wrigley, N. Retail and the urban. Urban Geogr. 2000, 21, 640-653. [CrossRef]

37. Navarro, C. Las Dimensiones Culturales de la Ciudad; Catarata: Madrid, Spain, 2012.

38. Mateos, C. Escenas Culturales: Una Aplicación al Análisis de las Ocupaciones Creativas y las Desigualdades Territoriales en España. Doctoral Thesis, Universidad Pablo de Olavide, Sevilla, Spain, 2016.

39. Meltzer, R.; Schuetz, J. Bodegas or Bagel Shops? Neighborhood Differences in Retail and Household Services. Econ. Dev. Q. 2012, 26, 73-94. [CrossRef]

40. Guy, C. Neighbourhood retailing and food poverty: A case study in Cardiff. Int. J. Retail Distrib. Manag. 2004, 32, 577-581. [CrossRef]

41. Schuetz, J.; Kolko, J.; Meltzer, R. Is the 'Shop Around the Corner' a Luxury or a Nuisance? The Relationship between Income and Neighborhood Retail Patterns. Available online: https://ssrn.com/abstract=1681734 (accessed on 23 September 2010).

42. Alwitt, L.; Donley, T. Retail stores in poor neighborhoods. J. Consum. Aff. 1997, 31, 139-164. [CrossRef]

43. Powell, L.; Slater, S.; Mirtcheva, D.; Bao, Y.; Chaloupka, F.J. Food store availability and neighborhood characteristics in the United States. Prev. Med. 2007, 44, 189-195. [CrossRef] [PubMed]

44. Bianchini, F.; Dawson, J.; Evans, R. Flagship projects in urban regeneration. In Rebuilding the City: Property-Led Urban Regeneration; Healey, P., Davsudi, S., Toole, M.O., Tavsanoglu, S., Usher, D., Eds.; Spon Press: London, UK, 1992; pp. $245-255$.

45. Loftman, P.; Nevin, B. Prestige Projects and Urban Regeneration in the 1980s and 1990s: A review of benefits and limitations. Plan. Pract. Res. 1995, 10, 299-316. [CrossRef]

46. Bedington, E. The Regeneration Game; The Grocer: Crawley, UK, 2001; pp. 36-38.

47. Wrigley, N.; Guy, C.M.; Lowe, M.S. Urban regeneration, social inclusion and large store development: The Seacroft development in context. Urban Stud. 2002, 39, 2101-2114. [CrossRef] 
48. Simó López, M.; Casellas, A.; Avellaneda, P. Comercio minorista y peatonalización: Evolución y adaptación en la ciudad costera de Malgrat de Mar (Barcelona). An. Geogr. UCM 2018, 38, 219-238. [CrossRef]

49. Lowe, M. The Regional Shopping Centre in the Inner City: A Study of Retail-led Urban Regeneration. Urban Stud. 2005, 42, 449-470. [CrossRef]

50. Dixon, T.J. The Role of Retailing in Urban Regeneration. Local Econ. 2005, 20, 168-182. [CrossRef]

51. Gutiérrez, V.E. El comercio y la regeneración urbana de la ciudad una estrategia integral de marketing de ciudades. Distrib. Consumo 2005, 5, 40-49.

52. Confederación Argentina de la Mediana Empresa. Available online: https://www.redcame.org.ar/sectores/5/comercio-yservicios (accessed on 23 March 2021).

53. Mateos, C.M.; Navarro, C.J. El barrio como contexto cultural: El impacto de la iniciativa URBAN en los espacios de consumo cultural. In Lógicas e Impactos de la Estrategia Integral en Políticas Urbanas; Navarro, C.J., Rodriguez-García, M.J., Guerrero Mayo, M.J., Eds.; Icaria: Barcelona, Spain, 2020; pp. 129-140.

54. Jones, P.; Hillier, D.; Comfort, D. Urban regeneration companies and city centres. Manag. Res. News 2003, 26, 54-63. [CrossRef]

55. Brama, A. The Effects of Neighbourhood Regeneration on the Neighbourhood Hierarchy of the Cities. In Understanding Neighbourhood Dynamics; van Ham, M., Manley, D., Baley, N., Simpson, L., Maclennan, D., Eds.; Springer: New York, NY, USA, 2013; pp. 111-138.

56. Wei, F.; Knox, P.L. Neighborhood Change in Metropolitan America, 1990 to 2010. Urban Aff. Rev. 2014, 50, 459-489. [CrossRef]

57. Lawless, P. Continuing dilemmas for area based urban regeneration: Evidence from the New Deal for Communities Programme in England. People Place Policy 2007, 1, 14-21. [CrossRef]

58. O'Reilly, D. Comment on Rhodes et al. (2005): Some further thoughts on assessing the effects of area-based initiatives on local outcomes. Urban Stud. 2007, 44, 1145-1153. [CrossRef]

59. Rossi, P.H. Evaluating Community Development Programs: Problems and Prospects. In Urban Problems and Community Development; Ferguson, R.F., Dickens, W.T., Eds.; The Brookings Institution: Whasington, DC, USA, 1999; pp. 521-568.

60. Abadie, A. Difference-in-difference estimators. In The New Palgrave Dictionary of Economics; Palgrave: London, UK, 2008.

61. Blunderr, R.; Dosta, M. Evaluation methods for non-experimental dara. Fisc. Stud. 2000, 21, 427-468. [CrossRef]

62. Marlet, G.; Van Woerkens, C. De Effectiviteit van Grotestedenbeleid: Kwantitatieve Evaluatie GSB III, 2005-2009; Atlas voor gemeenten: Utrecht, The Netherlands, 2010.

63. Mateos-Mora, C.; Zapata-Moya, A. El impacto de los planes de regeneración en el asociacionismo. In Innovación en Políticas Urbanas: Perspectivas, Metodologías y Casos; Clemente, J.N., Ed.; Icaria Editorial: Barcelona, Spain, 2019; pp. $133-142$.

64. Coulson, N.E.; Leichenko, R.M. Historic Preservation and Neighbourhood Change. Urban Stud. 2004, 41, 1587-1600. [CrossRef]

65. Jayantha, W.M.; Yung, E.H.K. Effect of Revitalisation of Historic Buildings on Retail Shop Values in Urban Renewal: An Empirical Analysis. Sustainability 2018, 10, 1418. [CrossRef]

66. Mateos, C.M.; Navarro, C.J. La localización de la clase creativa. Empiria 2014, 29, 123-153.

67. Zukin, S. The Culture of Cities; Oxford: Blackwell, UK, 1995.

68. Zukin, S.; Trujillo, V.; Frase, P.; Jackson, D.; Recuber, T.; Walker, A. New retail capital and neighborhood change: Boutiques and gentrification in New York City. City Community 2009, 8, 47-64. [CrossRef]

69. Shirvani, A.; Sargolini, M.; Pierantoni, I.; Stimilli, F. Toward an innovative strategic approach for sustainable managment of natural protected areas in Italy. Geogr. Environ. Sustain. 2020, 13, 68-75. 